\title{
Solubility study and thermal stability analysis of calcium propionate
}

\author{
Tao Li ${ }^{1 *}$, Heike Lorenz ${ }^{1}$, Andreas Seidel-Morgenstern ${ }^{1,2}$ \\ 1, Max Planck Institute for Dynamics of Complex Technical Systems, Magdeburg, Germany. \\ 2, Otto-von-Guericke University, Institute of Process Engineering, Chair for Chemical Process \\ Engineering, Magdeburg, Germany. \\ *, Corresponding author e-mail address: li@mpi-magdeburg.mpg.de
}

\begin{abstract}
The solubilities in water within a temperature range between $10^{\circ} \mathrm{C}$ and $80^{\circ} \mathrm{C}$ and the thermal behavior of the frequently used food additive calcium propionate were investigated in order to clarify deviations in published data. Furthermore, solubilities in ethanol/water mixtures with the ethanol fraction range between $0 \%$ and $80 \%$ at $30^{\circ} \mathrm{C}$ were measured. Material purified by recrystallization was used to exclude that impurities have no influence on the solubility data. Consideration of the dissociation process of calcium propionate in aqueous solution shows that the particular shapes of the solubility curves can not be attributed to changes in $\mathrm{pH}$. The thermal stability and phase behavior of calcium propionate was investigated using TG-DSC and DSC combined with temperature-resolved XRPD. The substance initially provided turned out to be a mixture of the monohydrate and the anhydrous calcium propionate. The solid phases obtained under equilibrium conditions in the solubility experiments in water and also in the mixed solvents were identified as the monohydrate. The conversion of the monohydrate to anhydrous calcium propionate is connected with a dehydration enthalpy of $\sim 46.5 \mathrm{~kJ} \mathrm{~mol}^{-1}$. A new polymorph of the anhydrous calcium propionate was found and characterized. The results obtained in this study provide a better understanding of calcium propionate and support the development of improved crystallization processes.
\end{abstract}

Key words: calcium propionate; solubility; solid-state characterization; thermal analysis

\section{Introduction}

Calcium propionate appears as a white crystalline solid or powder with odors resembling propionate acids $[1,2]$. It is mainly used as preservative in a broad variety of products, especially in the manufacturing of baked goods. The antimicrobial action of calcium propionate is based on its dissociation process to produce undissociated propionate acid, which could diffuse across the cytoplasmic membrane and on the one hand releases a proton to increase the energy consumption of the organism for removing the proton out, while on the other hand accumulates in the cell and blocks metabolism by inhibiting enzymes [3]. Therefore the $\mathrm{pH}$ value of the substance to be preserved is of great importance to the antimicrobial action [2]. Typical concentration of calcium propionate used in bread producing is $0.2 \%$ based on the flour weight [4]. No flavor or lip feel is detectable when the concentration of calcium propionate in aqueous solutions ranges between 30 and $50 \mathrm{mM}$, which could be used with chlorinated water as a sanitary treatment for fresh-cut melon [5]. Calcium propionate is more widely used than propionic acid because it is easier to handle the solid salt than the corrosive liquid acid [3, 4]. The common method employed for the preparation of calcium propionate is the neutralization of propionic acid with calcium hydroxide in aqueous solution. The methods to achieve the solid products include spray drying, evaporation crystallization in aqueous solution or a solvent-free process, which could cause environment pollution and 
high costs or strong aggregation problems [6]. So improving the solid-liquid separation process, which includes the design of an optimal crystallization process to produce calcium propionate with desired CSD, shape and solid-state form as well as with low energy consumption and simplified procedures, is of crucial importance.

Crystallization is a key technology used as a purification and isolation process both on a laboratory and an industrial scale in a wide variety of chemical engineering fields. The solids produced in crystallization processes based on different operation could have various physical and chemical properties such as crystal size distribution (CSD), crystal morphology and solid-state form, which have a strong effect on the final product properties (e.g. dissolution behavior, bioavailability, density, etc.), as well as on the efficiency of the downstream processes (such as filtration, drying etc.) [7, 8]. It is well known that equilibria between solid and liquid phases are of crucial importance for the design of industrial crystallization processes [9]. Solubility values of the substance in a specified solvent provide information of supersaturation, which mainly determines the crystallization dynamics such as nucleation and growth behavior, as well as yield. If a single solvent cannot satisfy the request of the crystallization process, the combination of two or more intermiscible solvents would be chosen and the solid phases in the mixed solvents are necessary to be determined [10].

The solubility data of calcium propionate in water was determined by Krasnicki in 1887, who obtained the results from experiments made by heating and also by cooling a solution to the desired saturation temperature (heating and cooling method rep.) [11]. In 1902 Lumsden [12] determined solubility data and found a broad deviation from the results of Krasnicki. In Lumsden's solubility experiments, a thermostat to achieve a constant temperature was suggested, and a device used to remove the suspensions out with subsequent vacuum filtration to obtain the saturated solid-free liquid was devised [12, 13]. Lumsden [12] also analyzed the solids in contact with the solution by weighing the mass of solids and then converting the calcium propionate into calcium sulfate and subsequently weighing the mass of calcium sulfate. His results showed that the solids contained 1 mole of water. Furthermore, Walker and Fyffe [14] also obtained quite different results from those of Krasnicki for determining the solubility of barium acetate. They also verified that Krasnicki's results for the higher temperature were not valid. In study of Seidel [15], Krasnicki's solubility results for barium acetate were considered as incorrect as well. Wing and Thompson [13] examined the solubility data of Krasnicki for barium propionate and got a significantly different solubility curve which was convex to the temperature axis, and not concave as Krasnicki described. Obviously in [16] the solubility of calcium propionate in water was cited from ref. [12]. One patent [17] describes that calcium propionate has got a solubility minimum at $55^{\circ} \mathrm{C}$, while another one [6] expresses this minimum solubility to be at $50^{\circ} \mathrm{C}$. To clarify the observed deviations of the solubility behavior, the comprehensive solubilities of calcium propionate in water were re-examined in this paper. XRPD were performed to characterize the solid-state form in solubility experiments.

It is well known that impurities may affect the solubility of a solute. Microimpurities can influence phenomena at crystal-liquid interfaces $[9,18]$. In this work, the specific solubility behavior of calcium propionate raises obvious concerns regarding the effect of microimpurities on the solubility data. Since the purity of the substance received from the supplier was specified with $>98 \%$, recrystallization of calcium propionate was performed to further increase the purity and to analyze the influence of the microimpurities on the solubility data. 
It is clear now that the change of the $\mathrm{pH}$ value leads to a shift of the equilibrium of ionization process, which causes an increase or decrease of solubility of calcium propionate [19]. Thus the dissociation behavior of calcium propionate aqueous solution with regard to temperature was studied to analyze the effect of ionization process on the solubility of calcium propionate in water.

In order to evaluate the solid phase behavior at higher temperatures and also to obtain the information of occurrence of further solid phases, thermal behavior and solid phase identity of a substance should be analyzed. Researchers [20, 21, 22, 23] have studied the thermal properties of calcium propionate using TG, DTA, and DSC. However, the solid phase behavior of calcium propionate with respect to temperature is not clear and the identity of the solid phases is still missing. In this paper, thermal stability and solid phase behavior of calcium propionate was analyzed by simultaneous TG-DSC and separately performed DSC in a closed crucible both under dry helium. Complementary temperature-resolved XRPD studies were performed to elaborate the solid-state behavior and the phase identity at different temperatures.

\section{Experimental}

\subsection{Materials and analytical methods}

Anhydrous calcium propionate was purchased from ACROS ORGANICS Company, 98\% + purity, CAS No. 4075-81-4. According to the impurities information provided by the supplier, the content of water insoluble materials and heavy metals in the substance purchased are less than $0.3 \%$ and $0.01 \%$, respectively. Deionized water and ethanol (purity $\geq 99.7 \%$, VWR Chemicals) were used as solvents during solubility measurements. The substances were used as obtained.

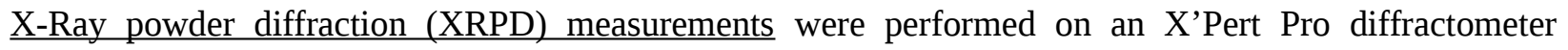
(PANalytical GmbH, Germany) with $\mathrm{Cu}-\mathrm{K} \alpha$ radiation. XRPD scans were recorded in continuous mode with a step size of $0.017^{\circ}$ and a counting time of $50 \mathrm{~s}$ per step over an angular range of $3-40^{\circ} 2$ Theta. Samples were prepared on background-free sample holders. In order to analyze the phase behavior with respect to temperature, temperature-resolved XRPD measurements in a temperature range of $30-305^{\circ} \mathrm{C}$ were applied. A typical heating-cooling program is as follows: the samples were heated stepwise from $30^{\circ} \mathrm{C}$ to $305^{\circ} \mathrm{C}$ with a heating rate of $5 \mathrm{~K} / \mathrm{min}$, and subsequently cooled with a cooling rate of $5 \mathrm{~K} / \mathrm{min}$ from $305^{\circ} \mathrm{C}$ to $140^{\circ} \mathrm{C}$ and $10 \mathrm{~K} / \mathrm{min}$ from $140^{\circ} \mathrm{C}$ to $30^{\circ} \mathrm{C}$. At certain temperatures $\left(30^{\circ} \mathrm{C}, 140^{\circ} \mathrm{C}, 230^{\circ} \mathrm{C}\right.$, $305^{\circ} \mathrm{C}$ ), the samples were kept isothermal for equilibrium and to measure the diffraction patterns at this temperature. The temperatures were selected on the basis of the DSC and TG-DSC results.

DSC and simultaneous TG-DSC measurements were performed on a DSC 131 and a Sensys Evo (both Setaram, France) system respectively. The samples were taken from an freshly opened bottle, carefully crushed in an agate mortar and about $12 \mathrm{mg}$ thereof weighted into an Al-pan. The sample crucible is open for TG-DSC and closed for separately performed DSC. Samples are then subjected to heating from $30^{\circ} \mathrm{C}$ to $450^{\circ} \mathrm{C}$ with a heating rate of $5 \mathrm{~K} / \mathrm{min}$, while purging with helium at flow rates of $40 \mathrm{~mL} / \mathrm{min}$ and 20 $\mathrm{mL} / \mathrm{min}$, respectively.

pH-values were measured using a pH meter (SevenExcellence, Mettler Toledo, Switzerland). It allows measurements of both $\mathrm{pH}$ value $( \pm 0.002)$ and temperature $\left( \pm 0.1^{\circ} \mathrm{C}\right)$. Calibration was performed before the measurements. Around $7 \mathrm{~g}$ calcium propionate and around $70 \mathrm{~g}$ deionized water were dissolved in a beaker under magnetic stirring. The temperature of the beaker was controlled using a double jacketed 
vessel connected with a thermostat. A PT100 $\left( \pm 0.1^{\circ} \mathrm{C}\right)$ was used for in-line monitoring the temperature. At each point, the temperature measured by $\mathrm{pH}$ device and PT 100 was compared. In aqueous solution, calcium propionate dissociates into calcium and propionate ions. The latter is seen as the conjugate base of propionic acid. Ionized part can be calculated based on the values of $\mathrm{pKa}$ and $\mathrm{pH}$ of $10 \%$ calcium propionate aqueous solution $(\mathrm{w} / \mathrm{w})[24,25]$.

Ion chromatography was performed on a DIONEX ICS-1100 system (Thermo Scientific, USA) to analyze the composition of the commercial substance and recrystallized materials in particular to identify and quantify potential ionic impurities, as e. g. $\mathrm{Li}^{+}, \mathrm{NH}_{4}{ }^{+}, \mathrm{K}^{+}$cations and sulfate anions (that might form sparingly soluble salts with e. g. Ba or Sr present.). The columns used were IonPac CG16 (3×50 mm) and IonPac CS16 $(3 \times 250 \mathrm{~mm})$, respectively. The eluent applied were $30 \mathrm{mM}$ methanesulfonic acid solution and $4.5 \mathrm{mM} \mathrm{Na}_{2} \mathrm{CO}_{3} / 1.4 \mathrm{mM} \mathrm{NaHCO}_{3}$ solution at flow rates of 0.4 and $1.2 \mathrm{~mL} / \mathrm{min}$, respectively.

\subsection{Solubility measurements of calcium propionate in water and ethanol/water mixtures}

The solubilities of calcium propionate were measured gravimetrically with an isothermal method. The substance bought was used as the starting material. Around $100 \mathrm{~g}$ deionized water or ethanol/water mixtures were put in a $250 \mathrm{~mL}$ double jacketed crystallizer equipped with mechanical agitation and a thermostat. A PT $100\left( \pm 0.1^{\circ} \mathrm{C}\right)$ was used for in-line monitoring and adjusting a certain temperature for the solubility measurement. Temperature stability was $\pm 0.1^{\circ} \mathrm{C}$. After the temperature was stable, excess solute was added gradually, and then the suspension was well mixed for at least $24 \mathrm{~h}$. When the solid-liquid system had reached equilibrium, the wet solids separated from the suspension were directly analyzed by XPRD to check the solid-state form for correlation with the solute in equilibrium in the saturated solution. Solution was drown using a syringe and filtered via a micro-filter, put in small vessels and dried in the oven at $150^{\circ} \mathrm{C}$ under atmospheric pressure for $4 \mathrm{~h}$. The clear saturated solution and dried solids were weighted respectively. Similarly, the dried solids were analyzed by XRPD as soon as taken from oven. At each data point, the experiments were repeated for three times, and the relative deviations of solubility values were estimated to be less than $0.5 \%$. Solubilities are then specified as g calcium propionate per 100 g solvent. Pure deionized water and solvent mixtures of ethanol and water with ethanol contents of $20 \%$, $40 \%, 60 \%$ and $80 \%(\mathrm{w} / \mathrm{w})$ respectively were used as solvents in the experiments. The solubilities in water were measured in a temperature range between $10^{\circ} \mathrm{C}$ and $80^{\circ} \mathrm{C}$, in ethanolic solutions solubilities refer to $30^{\circ} \mathrm{C}$.

\subsection{Recrystallization of calcium propionate}

Around 90 g original substance bought and 250 g deionized water were added into a crystallizer and dissolved under stirring for several hours by using a magnetic stirrer. The solution was filtered in order to remove the insoluble matter. The filtrate was then transferred to a glass beaker and put in the oven at $120^{\circ} \mathrm{C}$ under atmospheric pressure for a certain time. Then the temperature was decreased to $70^{\circ} \mathrm{C}$ and the beaker kept in the oven overnight. The solid-liquid suspensions were filtered and the filter cake was washed using $80 \%$ ethanol $/ 20 \%$ water $\left(\mathrm{w} / \mathrm{w}\right.$ ), then the solids were put into oven with $150^{\circ} \mathrm{C}$ for drying. The dry solid was weighed (18 g), analyzed by ion chromatography and used in solubility experiments in water at $30^{\circ} \mathrm{C}$ and $60^{\circ} \mathrm{C}$. 


\section{Results and discussion}

\subsection{Solubilities in water}

The solid phase should be properly characterized before and after the solubility measurement [26]. The powder patterns of solids from solubility measurements are shown in Fig. 1. The curve labelled with "bottle" refers to calcium propionate sampled from an fresh opened bottle bought from ACROS ORGANICS Company as presented before. The pattern shows three main sharp peaks at $\sim 7^{\circ}, \sim 8^{\circ}$ and $\sim 9^{\circ}$, and compared to the reference patterns of anhydrous calcium propionate and calcium propionate monohydrate [27, 28], the substance bought is clearly a mixture of both the anhydrous calcium propionate and the monohydrate. The curves of wet samples prepared from suspended solids during solubility measurements between $10^{\circ} \mathrm{C}$ and $80^{\circ} \mathrm{C}$ (labelled as " $10-80^{\circ} \mathrm{C}$ wet" in Fig. 1) exhibit many characteristic peaks, for example the sharp peak at $\sim 7^{\circ}$. All patterns show the presence of the same phase, small shifts in the 2 Theta positions are caused by the sample preparation procedure (some mg of wet unground samples). Comparison of the patterns with data from reported literature [27] verifies that monohydrate is the stable phase of calcium propionate in aqueous solution from $10^{\circ} \mathrm{C}$ to $80^{\circ} \mathrm{C}$. So the solubility data presented in the following relate to monohydrate $(\mathrm{H})$ as solid phase. The dry samples included in Fig. 1 were obtained by putting the solid-free saturated solution into oven at $150^{\circ} \mathrm{C}$ for 4 hours under atmospheric pressure, that was combination of recrystallization to obtain solids and drying at the same time. The patterns of dry samples (labelled as " $10-80^{\circ} \mathrm{C}$ dry" in Fig. 1) contain two sharp peaks at $\sim 8^{\circ}$ and $\sim 9^{\circ}$, indicating the dry samples were anhydrous calcium propionate (A) [28]. Thus, a drying method to achieve anhydrous calcium propionate can be derived then.

The solubilities of calcium propionate determined in this work and from literature $[11,12]$ are presented in Tab. 1 and illustrated in Fig. 2. It can be seen that all solubility curves are markedly convex to the temperature axis with minimal solubility values. The results from refs. [11, 12] indicate that the solubility decreases with increasing the temperature at low temperatures until reaching about $55^{\circ} \mathrm{C}$. Above this temperature, the solubility increases monotonously. In this work the solubility decreased when the temperature was increased from $10^{\circ} \mathrm{C}$ to $45^{\circ} \mathrm{C}$ reaching a minimal value at about $45^{\circ} \mathrm{C}$. Between $45^{\circ} \mathrm{C}$ and $60^{\circ} \mathrm{C}$, the solubility values kept almost constant. Above $60^{\circ} \mathrm{C}$, the solubility increased with increasing the temperature. The XRPD results shown in Fig. 1 verify that the solid-state form on the descending and ascending parts of the solubility curve is always the same, the monohydrate of calcium propionate.

It is found that our measured solubility values are lower than those in refs. [11, 12], with the Lumsden values [12] being the highest. By comparing our results with Lumsden's, we can find that relative deviations range from $\sim 2 \%$ to $\sim 5 \%$, e.g. at $55^{\circ} \mathrm{C}$, the solubility values are 36.4 and $38.2 \mathrm{~g} / 100 \mathrm{~g}$ water, respectively, with the deviation reached $4.8 \%$. The deviation and possible causes are discussed in the following. First, in Lumsden's solubility experiments, the substance was obtained by the reaction of dilute propionic acid and calcium carbonate with the subsequent recovery of products by evaporating the liquid over a water-bath and drying in air [12, 13]. The purity of final products was not given. Possible acid residuals or other impurities could influence the solubility results. Also, the solubility of calcium propionate in ref. [12] was determined by converting the calcium propionate into calcium sulfate and subsequently weighing the mass of calcium sulfate. It is known that calcium sulfate occurs in three different forms: gypsum $\left(\mathrm{CaSO}_{4} \cdot 2 \mathrm{H}_{2} \mathrm{O}\right)$, hemihydrate $\left(\mathrm{CaSO}_{4} \cdot 0.5 \mathrm{H}_{2} \mathrm{O}\right)$ and anhydrite $\left(\mathrm{CaSO}_{4}\right)$. The transition temperatures of gypsum-anhydrite and gypsum-hemihydrate vary within a range of $42-60^{\circ} \mathrm{C}$ and $80-100^{\circ} \mathrm{C}[28,29]$, showing that anhydrite easily tends to moisture absorption. It is obvious that the 
solubility result measured at a certain temperature point would be higher than the real one if solvates generated during weighing the mass of calcium sulfate.

The solubilities measured for the recrystallized substance are also shown in Tab. 1 and Fig. 2 (data at $30^{\circ} \mathrm{C}$ and $60^{\circ} \mathrm{C}$ ). The results of ion chromatography showed that besides calcium ions only $\sim 0.45 \%$ sodium ions were present in the original substance purchased. No other cations or anions in accessible amounts were detected. After recrystallization more than $68 \%$ of the sodium (residual content $\sim 0.14 \%$ ) and also the insoluble matter were removed as purification results. The relative deviation between the solubility data of the original substance bought from company and the recrystallized materials is $0.6 \%$ and $0.7 \%$ for the two temperatures, respectively. This agrees with "microimpurities may generally have an impact on phenomena at the crystal-liquid interface but not solubility data" that is illustrated in ref. [18]. Thus the original substance could be used for measuring the solubility of calcium propionate.

Fig. 3 shows the values of pKa of propionic acid calculated [24] , values of $\mathrm{pH}$ measured, and values of ionized part of $10 \%$ calcium propionate in water $(\mathrm{w} / \mathrm{w})$ at different temperatures [25]. The values of $\mathrm{pKa}$ increase very slightly from 4.9 at $32^{\circ} \mathrm{C}$ to 5.0 at $76^{\circ} \mathrm{C}$, while $\mathrm{pH}$ values are found to fluctuate at around 7.2 as the temperature increases. The part of propionate ionized form remains around $99.5 \%$ with the maximum value being $99.6 \%$ at $41^{\circ} \mathrm{C}$. The results indicate that calcium and propionate ionized forms predominate in calcium propionate aqueous solution. It is worthwhile noted that the relative deviations of $\%$ ionized values at different temperatures are extremely small, with the maximum value being around $0.06 \%$, further verifying the shape of the solubility curve of calcium propionate not be attributed to the change of $\mathrm{pH}$.

The measured solubility data of calcium propionate monohydrate in water are fitted and could be expressed by the following quadratic equation:

$$
\frac{C^{i}}{[\text { g calcium propionate } / 100 \mathrm{~g} \text { water }]}=0.0019\left(\frac{T}{{ }^{\circ} \mathrm{C}}\right)^{2}-0.2056\left(\frac{T}{{ }^{\circ} \mathrm{C}}\right)+41.82 R^{2}=0.993
$$

\subsection{Solubilities in ethanol/water mixtures}

Results similar to works are observed investigating the solid phase behavior of calcium propionate in ethanol/water mixtures, as shown in Fig. 4. In all ethanol/water mixtures monohydrate is the stable phase in equilibrium. Thus the solubility data in ethanol/water mixtures relate to monohydrate as solid phase. Dry solids after recrystallization and drying of solution with ethanol fractions of $20 \%-80 \%$ (w/w) are anhydrous calcium propionate. However, when the solvent was changed to pure ethanol, the solids suspended in ethanol were mixture of the anhydrous calcium propionate and the monohydrate, with main portion being the anhydrous phase as in the starting material. The dry solids provided by recrystallization and drying of saturated ethanol solution show different phase behavior in pattern, for example, the splitting peaks rang between $8^{\circ}$ and $9^{\circ}$, were not observed in the patterns of anhydrous and monohydrate or their mixture.

Fig. 5 shows the solubilities of calcium propionate in ethanol/water mixtures with fractions of ethanol of $0 \%, 20 \%, 40 \%, 60 \%$ and $80 \%(\mathrm{w} / \mathrm{w})$ at $30^{\circ} \mathrm{C}$. In comparison to the solubilities in pure water at $30^{\circ} \mathrm{C}$, the solubility of calcium propionate monohydrate in ethanol/water mixtures decreases significantly with increasing ethanol content, e.g. only $16.93 \mathrm{~g}$ calcium propionate is dissolved at an ethanol fraction of 
$60 \%$, which is around $55 \%$ of the original value in water. It is worthwhile to be noted that the solubility of calcium propionate shows a strong dependence on the fraction of ethanol and decreases nearly linearly with the ethanol mass fraction, indicating the possibility of an anti-solvent crystallization process by adding ethanol into an aqueous solution to create supersaturation. This crystallization process will be investigated in future studies.

\subsection{Thermal stability and phase behavior of calcium propionate}

In order to investigate the solid phase of calcium propionate with respect to temperature, temperatureresolved XRPD measurements following the temperature profile as presented before were performed and the results are shown in Fig. 6. When the temperature was increased from $30^{\circ} \mathrm{C}$ to $140^{\circ} \mathrm{C}$, the characteristic peak of the monohydrate at $\sim 7^{\circ}$ disappeared, that is the hydrate water is released and only anhydrous material remained. The dehydrated form remained stable at $230^{\circ} \mathrm{C}$, but when heating to $305^{\circ} \mathrm{C}$, a new pattern appeared, with a very sharp peak observed between $8^{\circ}$ and $9^{\circ}$. This pattern looks similar to those of dry solids recrystallized from pure ethanol (Fig. 4). This might be a new polymorph of the anhydrous phase, but this cannot be derived clearly before discussing the TG-DSC results. With decreasing the temperature the backward transition was observed.

Fig. 7 presents the TG-DSC curve of original calcium propionate (as bought), Fig. 8 the related DSC curve measured separately in a closed crucible both under dry helium.

The first endothermic effect between $67^{\circ} \mathrm{C}$ and $112^{\circ} \mathrm{C}$ is connected with a mass loss of $0.82 \%$ observed in the TG plot shown in Fig. 7. Based on the XRPD curves in Fig. 6, it is linked to the loss of the hydrate water. That means although the substance was sold as anhydrous calcium propionate it contained around $9 \%$ mass percentage of the monohydrate. As already mentioned above calcium propionate easily tends to moisture absorption. A second drastic mass loss started from around $342^{\circ} \mathrm{C}$, causing a mass loss of around $27 \%$ until the final measurement accomplished. The decomposition process of calcium propionate has been studied by E. Gobert-Ranchoux and Niu [20, 23]. During this process, gaseous product 3-pentanone

$\mathrm{C}_{2} \mathrm{H}_{5} \mathrm{COC}_{2} \mathrm{H}_{5}$ was emitted and calcium carbonate $\mathrm{CaCO}_{3}$ was left. Because the heating process was stopped when the temperature reached $450^{\circ} \mathrm{C}$, only parts of anhydrous salts decomposed into calcium carbonate, causing a smaller mass loss of around $27 \%$ than the theoretical one of $46.3 \%$.

The heat flow curves shown in Fig. 7 and Fig. 8 can be divided into four stages. The first stage contains an endothermic peak with peak temperature of $83^{\circ} \mathrm{C}$ and $92.6^{\circ} \mathrm{C}$, respectively. This peak corresponds to the loss of hydrate water. This dehydration process could be confirmed by temperature-resolved XRPD measurements. As shown in Fig. 7, the XRPD curve at $30^{\circ} \mathrm{C}$ changed to the one at $140^{\circ} \mathrm{C}$ when the substance was heated from $30^{\circ} \mathrm{C}$ to $140^{\circ} \mathrm{C}$. The phase change is shown below:

$$
\mathrm{Ca}\left(\mathrm{C}_{2} \mathrm{H}_{5} \mathrm{CO}_{2}\right)_{2} \cdot \mathrm{H}_{2} \mathrm{O} \rightarrow \mathrm{Ca}\left(\mathrm{C}_{2} \mathrm{H}_{5} \mathrm{CO}_{2}\right)_{2}+\mathrm{H}_{2} \mathrm{O} \uparrow
$$

The dehydration process caused a heat effect of $\sim 21 \mathrm{~J} \mathrm{~g}^{-1}$ (mean value). The dehydration enthalpy of calcium propionate monohydrate can be obtained based on the heat consumed and the weight fraction of the monohydrate in the samples. E. Gobert-Ranchoux [20] stated that the dehydration heat value measured by DTA was $52.97 \mathrm{~kJ} \mathrm{~mol}^{-1}$. In this work the mean value of the dehydration enthalpy is calculated as $46.5 \mathrm{~kJ} \mathrm{~mol}^{-1}$ using TG-DSC and DSC in a closed crucible, which is close to the reported value [20]. 
As the temperature increased, small exothermic peaks were observed with peak temperatures of $198.9^{\circ} \mathrm{C}$ and $211.7^{\circ} \mathrm{C}$ in TG-DSC and $191.3^{\circ} \mathrm{C}$ and $211.8^{\circ} \mathrm{C}$ in separately performed DSC, respectively. These exothermic peaks are not accompanied by a mass loss shown in Fig. 7. Comparison between XRPD curves at $140^{\circ} \mathrm{C}$ and $230^{\circ} \mathrm{C}$ in Fig. 6, show that there is no change of the particular solid phase in that temperature region. Thus these effects can be attributed to change in crystallinity, i.e. recrystallization of some amorphous phase still present after dehydration. Since the sample was a heterogeneous mixture of monohydrate and anhydrate, no 'homogeneous' recrystallization occurred but rather two small events. A similar effect was also observed by E. Gobert-Ranchoux [20], according to the following reaction:

$$
\mathrm{Ca}\left(\mathrm{C}_{2} \mathrm{H}_{5} \mathrm{CO}_{2}\right)_{\text {2amorphous }} \rightarrow \mathrm{Ca}\left(\mathrm{C}_{2} \mathrm{H}_{5} \mathrm{CO}_{2}\right)_{2 \text { crystalline }}
$$

A second endothermic peak is observed at $272.1^{\circ} \mathrm{C}\left(\mathrm{T}_{\text {peak }}\right)$ in TG-DSC (Fig. 7) and at $272.6^{\circ} \mathrm{C}\left(\mathrm{T}_{\text {peak }}\right)$ in separate DSC (Fig. 8). The heat consumed is $4.4 \mathrm{~J} \mathrm{~g}^{-1}$ and $5.4 \mathrm{~J} \mathrm{~g}^{-1}$ for TG-DSC and DSC, respectively. No mass loss is observed from TG curve shown in Fig. 7. The study of temperature-resolved XRPD indicated a solid-phase transition occurring between $230^{\circ} \mathrm{C}$ and $305^{\circ} \mathrm{C}$. By combining the results of TG-DSC, DSC and temperature-resolved XRPD, it can be concluded that a polymorphic transformation of the anhydrous phase occurred and a new polymorph was obtained. The new polymorph is represented as anhydrous calcium propionate Form II (simplified as Form II in Fig. 9) compared to anhydrous calcium propionate Form I (Form I in Fig. 9). Thus this polymorphic transformation of the anhydrous calcium propionate of Form I $\rightarrow$ Form II is:

$$
\mathrm{Ca}\left(\mathrm{C}_{2} \mathrm{H}_{5} \mathrm{CO}_{2}\right)_{2 \text { FormI }} \rightarrow \mathrm{Ca}\left(\mathrm{C}_{2} \mathrm{H}_{5} \mathrm{CO}_{2}\right)_{2 \text { Form II }}
$$

As shown in Fig. 6, when the temperature decreased from $305^{\circ} \mathrm{C}$ to $230^{\circ} \mathrm{C}$, the backward transition of this polymorphic transformation was observed, showing the transition process between Form I and Form II to be reversible; thus these two polymorphs are related enantiotropically.

The largest endothermic transition, which is sharp and narrow with peak temperature of $394.5^{\circ} \mathrm{C}$ in TGDSC and $393.5^{\circ} \mathrm{C}$ in DSC, corresponds to the melting of anhydrous calcium propionate. A series of narrow and fluctuating peaks follows this sharp effect, characterizing the subsequent decomposition process of the sample, confirmed also by the rapid mass loss in the TG curve.

The XRPD patterns of the four different materials investigated in this work together with their preparation procedure are summarized in Fig. 9.

\section{Summary and Conclusions}

In this work the solubility and thermal behavior of calcium propionate was investigated. In solubility experiments an isothermal method was applied combined with gravimetric measurements. Solubilities of calcium propionate in water in the range between $10^{\circ} \mathrm{C}$ and $80^{\circ} \mathrm{C}$ were determined. The solubility in water decreases when the temperature is increased from $10^{\circ} \mathrm{C}$ to $45^{\circ} \mathrm{C}$. Between $45^{\circ} \mathrm{C}$ and $60^{\circ} \mathrm{C}$, the solubility values kept almost constant. Above $60^{\circ} \mathrm{C}$, the solubility increases with increasing temperature. Material purified by recrystallization was used in additional solubility experiments at $30^{\circ} \mathrm{C}$ and $60^{\circ} \mathrm{C}$ to evaluate possible effects of small amounts of impurities. It is turned out that the materials purchased and used without further purification (specified with $>98 \%$ purity) could be used for solubility determination of calcium propionate. 
The dissociation process of $10 \%$ calcium propionate aqueous solution (w/w) was also studied at different temperatures. The results obtained show that the ionized forms remain stable in the temperature range between $32^{\circ} \mathrm{C}$ and $76^{\circ} \mathrm{C}$. The particular shape of the solubility curve of calcium propionate is not attributed to changes of $\mathrm{pH}$. Solubilities of calcium propionate in ethanol/water mixtures with the ethanol fraction range between $0 \%$ and $80 \%(\mathrm{w} / \mathrm{w})$ at $30^{\circ} \mathrm{C}$ were also measured. It is shown that the solubility decreases nearly linearly with increasing the fraction of ethanol. These results suggest applying low energy consuming crystallization processes using mixed solvents.

XRPD was used for allocating the solid-state form in solubility experiments. It is verified that monohydrate is the stable phase of calcium propionate in aqueous solution from $10^{\circ} \mathrm{C}$ to $80^{\circ} \mathrm{C}$ and at $30^{\circ} \mathrm{C}$ in ethanol/water mixtures within the ethanol fraction range between $0 \%$ and $80 \%(\mathrm{w} / \mathrm{w})$.

Thermal behavior and solid-phase identity of calcium propionate was analyzed using TG-DSC and temperature-resolved XRPD. The thermal behavior of calcium propionate in dry helium could be divided into four parts: dehydration process (i.e. conversion of the monohydrate to the anhydrous calcium propionate), recrystallization of residual amorphous calcium propionate in the anhydrous phase formed, polymorphic transformation of the anhydrous phase and melting with subsequent decomposition. It is turned out that the substance purchased was a mixture of the anhydrous calcium propionate and the monohydrate. The dehydration enthalpy of the monohydrate was measured about $46.5 \mathrm{~kJ} \mathrm{~mol}^{-1}$. A new polymorph of the anhydrous phase was found and characterized (anhydrous calcium propionate Form II). The polymorphic phase transition is reversible and occurs at $\sim 270^{\circ} \mathrm{C}$ (onset temperature of TGDSC/DSC). The two polymorphs are related enantiotropically. Fusion occurred at $\sim 391^{\circ} \mathrm{C}$ (onset temperature of TG-DSC/DSC) directly followed by decomposition.

The results obtained in the current study contribute to better understand calcium propionate. They are seen as of importance for the development of improved crystallization processes providing calcium propionate.

\section{Acknowledgments}

The authors thank Jacqueline Kaufmann and Stefanie Leuchtenberg for supporting the analytical work. The support of the "International Max Planck Research School (IMPRS) for Advanced Methods in Process and System Engineering (Magdeburg)” is gratefully acknowledged.

\section{References}

[1] W. M. Haynes, D. R. Lide, CRC handbook of chemistry and physics: a ready-reference book of chemical and physical data, 91st ed., CRC Press, Boca Raton 2010

[2] L. Erich, J. Martin, Antimicrobial Food Additives, Springer, Heidelberg 1997

[3] R. W. Hutkins, Microbiology and technology of fermented foods, 2nd ed., Wiley-Blackwell, Hoboken 2006

[4] J. D. Legan, Int. Biodeter. Biodegr. 1993, 32(1-3), 33-53. DOI: 10.1016/0964-8305(93)90038-4

[5] R. A. Saftner, J. Bai, J. A. Abbott, Y. S. Lee, Postharvest Biol. and Tec. 2003, 29(3), 257-269. DOI: 10.1016/S0925-5214(03)00041-3

[6] F. Lämmermann, C. Lockemann, Albert Margin, EP1072581 A2, 2001 
[7] G. Liu, T. B. Hansen, H. Qu, et al., Chem. Eng. Technol. 2014, 37(8), 1297-1304. DOI: 10.1002/ceat.201400206

[8] Z. K. Nagy, G. Fevotte, H. Kramer, L. L. Simon, Chem. Eng. Res. Des. 2013, 91(10), 1903-1922. DOI: http://dx.doi.org/10.1016/j.cherd.2013.07.018

[9] H. Lorenz, in Crystallization (Ed: W. Beckmann), Wiley-VCH, Weinheim 2013, 35-74

[10] E. Horosanskaia, A. Seidel-Morgenstern, H. Lorenz, Thermochim. Acta 2014. 578, 74-81. DOI: 10.1016/j.tca.2013.12.019

[11] Emil Ritter v. Krasnicki, Monatsh Chem. Verw. Teile anderer Wiss. 1887, 8(1), 595-606. DOI: 10.1007/BF01510084

[12] J. S. Lumsden, J. Chem. Soc., Trans. 1902, 81(0), 350-362. DOI: 10.1039/CT9028100350

[13] H. J. Wing, T. J. Thompson, J. Am. Chem. Soc. 1926, 48(1), 104-106. DOI: 10.1021/ja01412a014

[14] J. Walker, W. A. Fyffe, J. Chem. Soc., Trans. 1903, 83(0), 173-182. DOI: 10.1039/CT9038300173

[15] S. Atherton, Solubilities of inorganic and organic compounds: a compilation of solubility data from the periodical literature, Van Nostrand, New York 1952

[16] S. Atherton, Solubilities of inorganic and organic compounds; a compilation of quantitative solubility data from the periodical literature, Van Nostrand, New York 1919

[17] D. Merkel, W. Muehlthaler, H. Diem, G. Matthias, US4700000 A, 1987

[18] H. Lorenz, B. Wolfgang, in Crystallization (Ed: W. Beckmann), Wiley-VCH, Weinheim 2013, 129148.

[19] P. H. Stahl, C.G. Wermuth, Handbook of pharmaceutical salts: properties, selection, and use, WileyVCH, Zürich 2008

[20] E. Gobert-Ranchoux, F. Charbonnier, J. Therm. Anal. 1977, 12(1), 33-42. DOI: 10.1007/BF01909853

[21] C. A. O'Connell, D. Dollimore, Thermochim. Acta 2000, 357-358, 79-87. DOI: 10.1016/S00406031(00)00371-3

[22] A. Valor, E. Reguera, E. Torres-García, S. Mendoza, F. Sanchez-Sinencio, Thermochim. Acta 2002, 389(1-2), 133-139. DOI: 10.1016/S0040-6031(02)00010-2

[23] S. Niu, K. Han, C. Lu, Chinese Sci. Bull. 2011, 56(12), 1278-1284. DOI: 10.1007/s11434-010-40658

[24] In-Ja Lee, Gang-Sook Jung, K. Kim, J. Solution Chem. 1994, 23(12), 1283-1292. DOI: 10.1007/BF00974181

[25] A. Albert, E. P. S., The Determination of Ionization Constants: A Laboratory Manual, Springer, Dordrecht, The Netherlands 1984

[26] G. T. Hefter, R. P. T. Tomkins, The Experimental Determination of Solubilities, 1st ed., Wiley, Chichester 2003

[27] F. Charbonnier, R. Gobert-Ranchoux, R. Faure, J. Appl. Cryst. 1977, 10(4), 357-358. DOI: 10.1107/S0021889877013648

[28] P. G. Klepetsanis, E. Dalas, P. G. Koutsoukos, Langmuir 1999, 15(4), 1534-1540. DOI: 10.1021/la9800912

[29] D. Freyer, W. Voigt, Monatsh. Chem. 2003, 134, 27. DOI: 10.1007/s00706-003-0590-3 


\section{Figure legends}

Figure 1. Overlay of XRPD patterns of calcium propionate solid phases from solubility measurements in water. Temperatures refer to saturation temperatures in solubility measurements. " $10-80^{\circ} \mathrm{C}$ wet" represents XRPD curves of solids in equilibrium in solubility experiments; " $10-80^{\circ} \mathrm{C}$ dry" represents XRPD curves of dry solids obtained by putting the solid-free saturated solution into oven at $150^{\circ} \mathrm{C}$ for 4 hours under atmospheric pressure; "Bottle" represents the XRPD curve of the original substance bought. Below available powder diffraction patterns of calcium propionate monohydrate from ref. [27] and anhydrous calcium propionate from ref. [28] are plotted for comparison. (PDF database, PANalytical $\mathrm{GmbH}$, Germany). For easy identification of the present phases, symbols " $\mathrm{H}$ " for Monohydrate and "A" for Anhydrate are introduced.
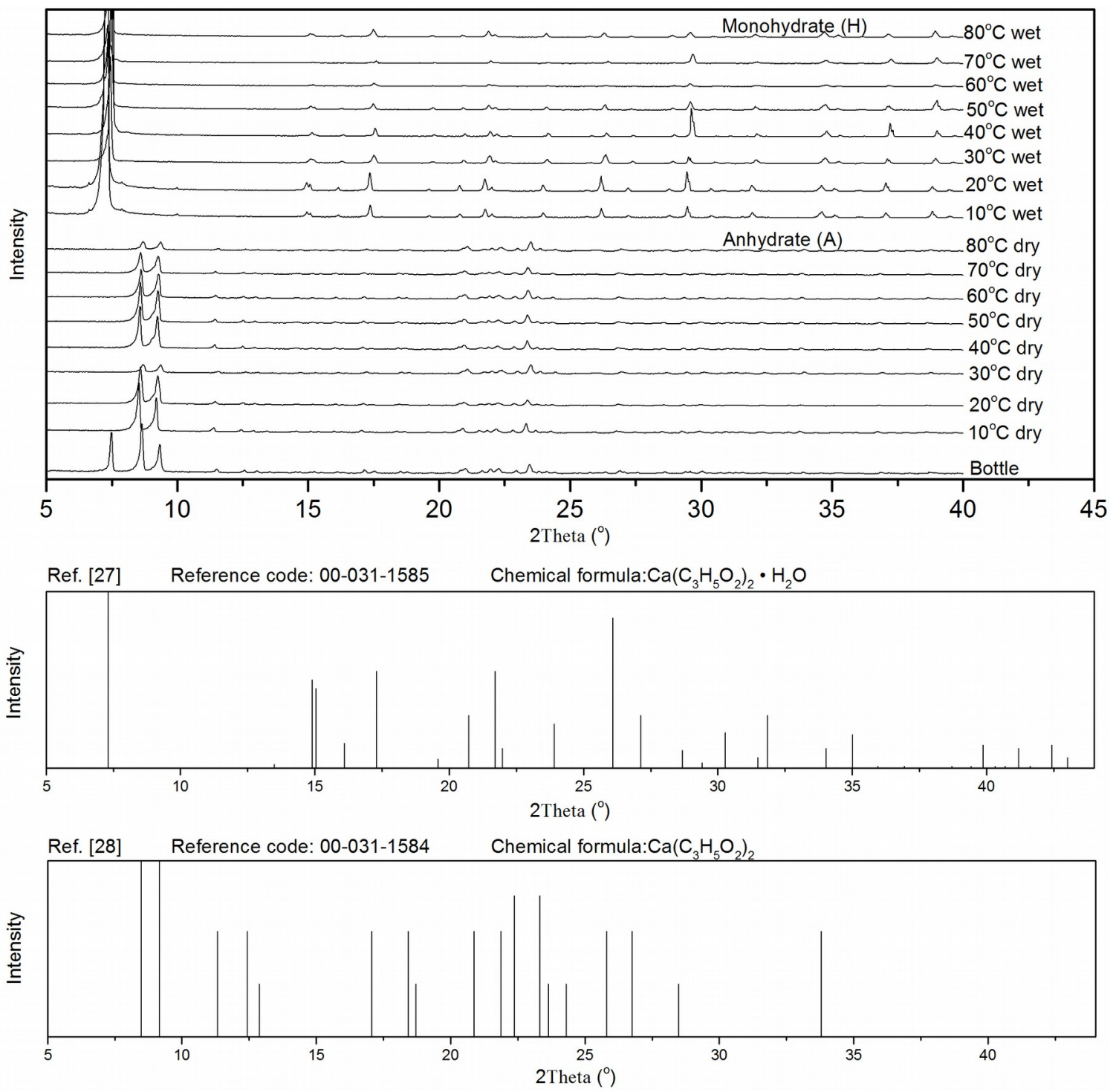
Figure 2. Solubilities of calcium propionate monohydrate in water as a function of temperature T: ( $\square$ ) ref. [12], ( $\square$ ) ref. [11] cooling method, ( $\square$ ) ref. [11] heating method, ( $\square$ ) this work without further purification, ( $\square$ ) this work purified by recrystallization.

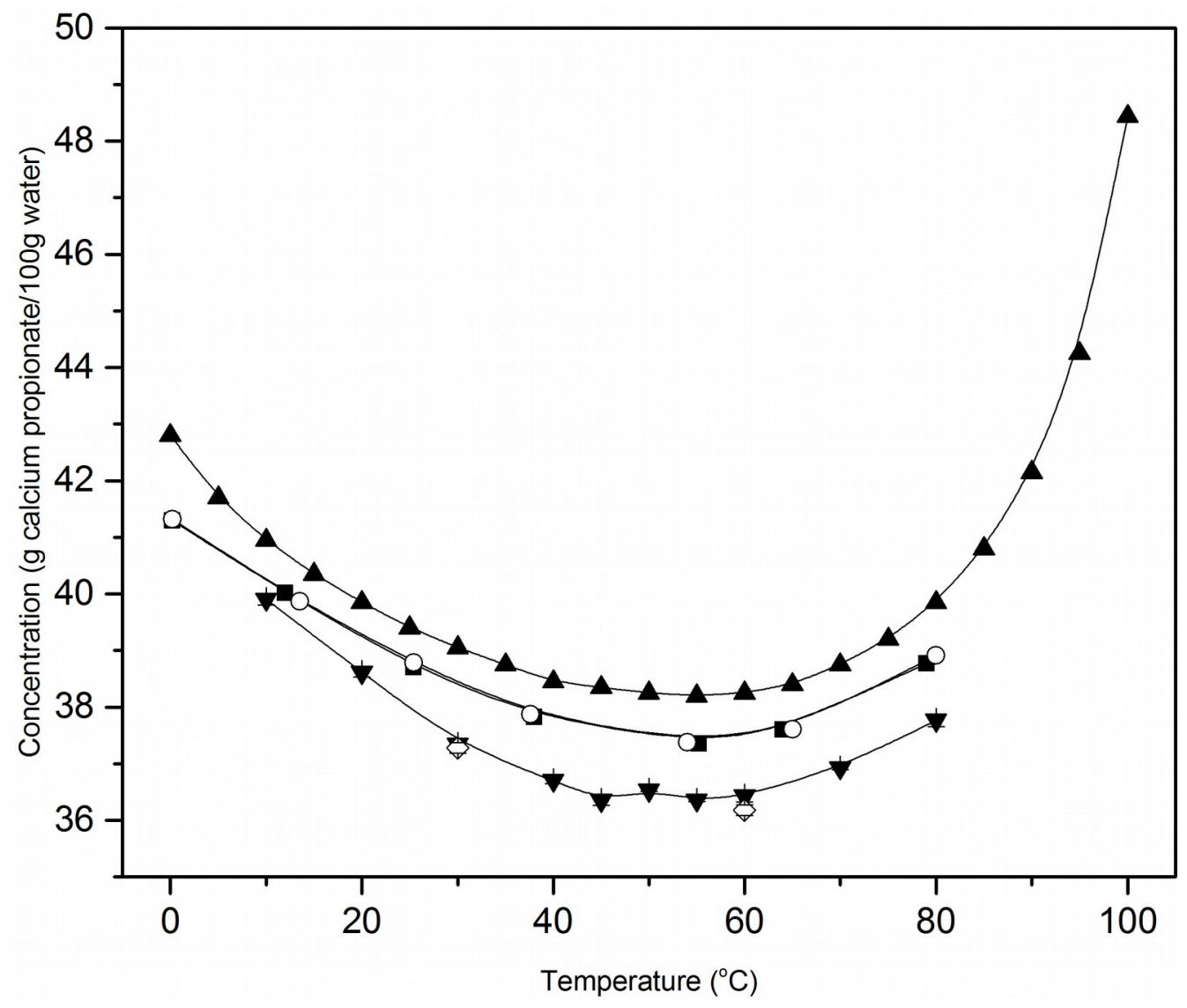


Figure 3. ( $\square$ ) Values of pKa of propionic acid calculated [30], ( $\square$ ) $\mathrm{pH}$ of $10 \%$ calcium propionate/water $(\mathrm{w} / \mathrm{w})$ solution measured, $(\square)$ ionized part of $10 \%$ calcium propionate/water (w/w) solution, with temperature.

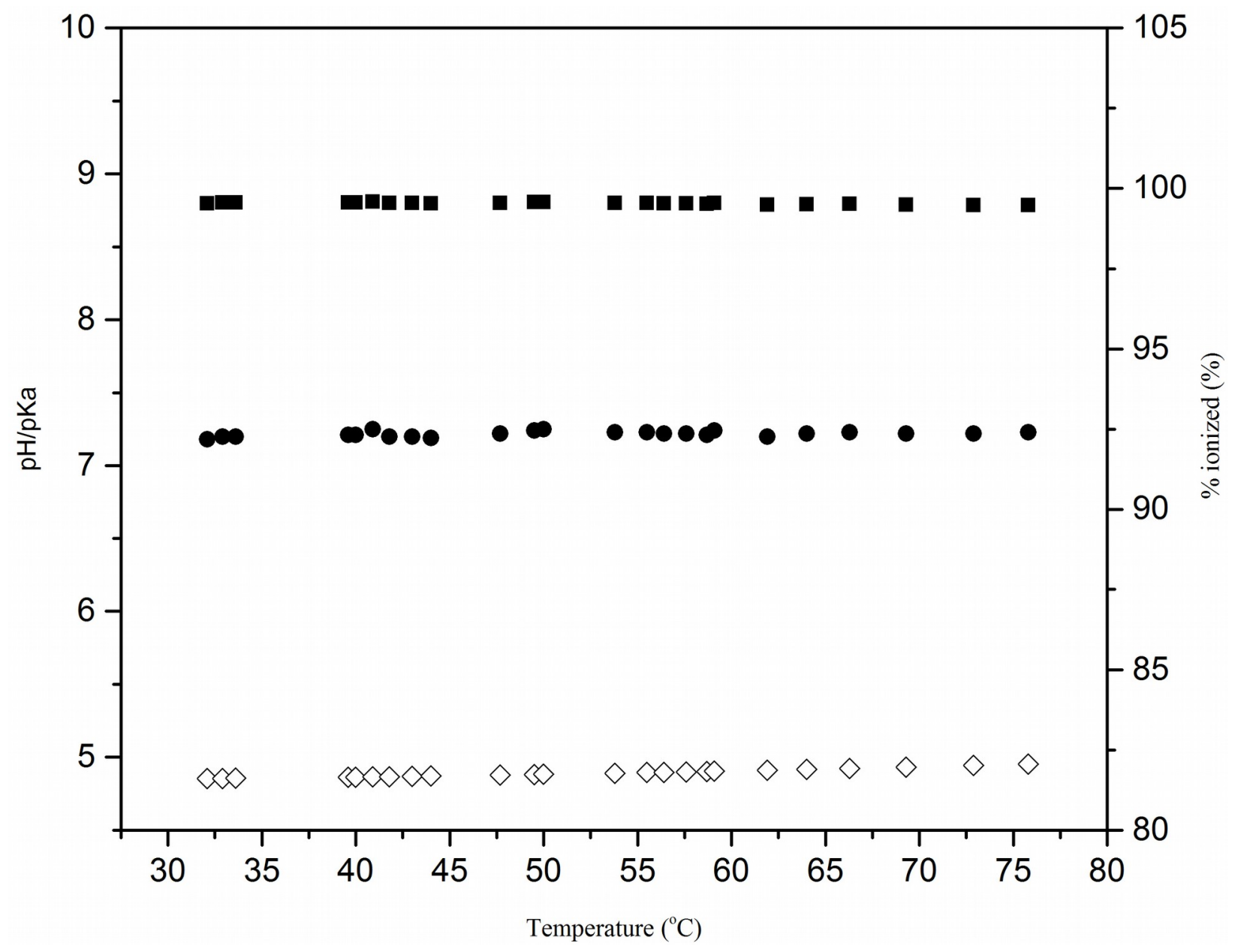


Figure 4. Overlay of XRPD patterns of calcium propionate from solubility measurements in ethanol/water mixtures at $30^{\circ} \mathrm{C}$. " $20 \%-80 \%$ wet and dry" represent XRPD curves of samples from the suspended solids and dry solids after recrystallization and drying of solution with ethanol fractions of 20\%-80\%; "ethanol wet and dry" represent XRPD curves with pure ethanol as solvent; " $30^{\circ} \mathrm{C}$ water wet" and " $30^{\circ} \mathrm{C}$ water dry" XRPD curves with pure water as solvent. " $\mathrm{H}$ ” and " $\mathrm{A}$ ” represent monohydrate and anhydrous calcium propionate phases, respectively.

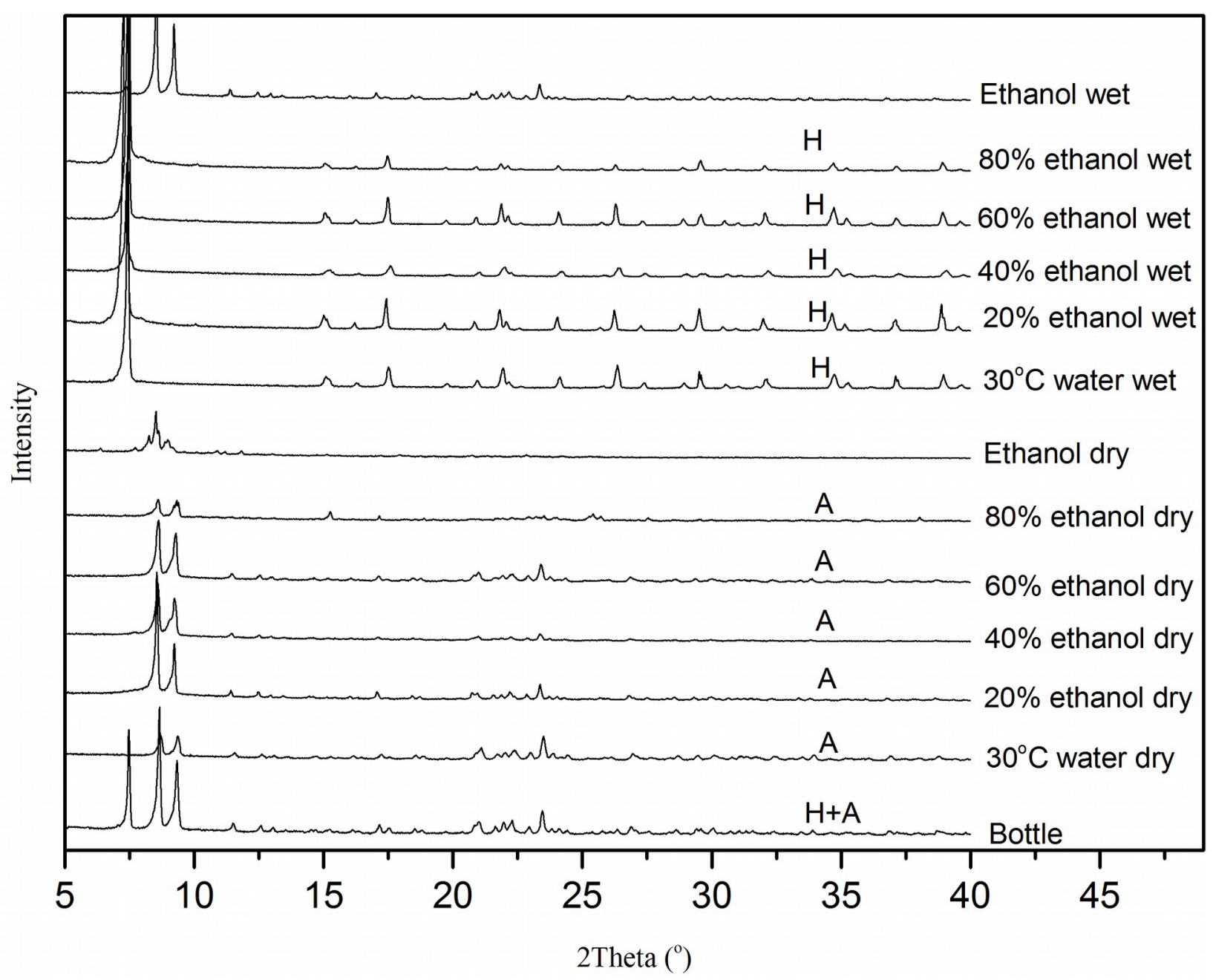


Figure 5. Solubilities of calcium propionate in ethanol/water mixtures at $30^{\circ} \mathrm{C}$.

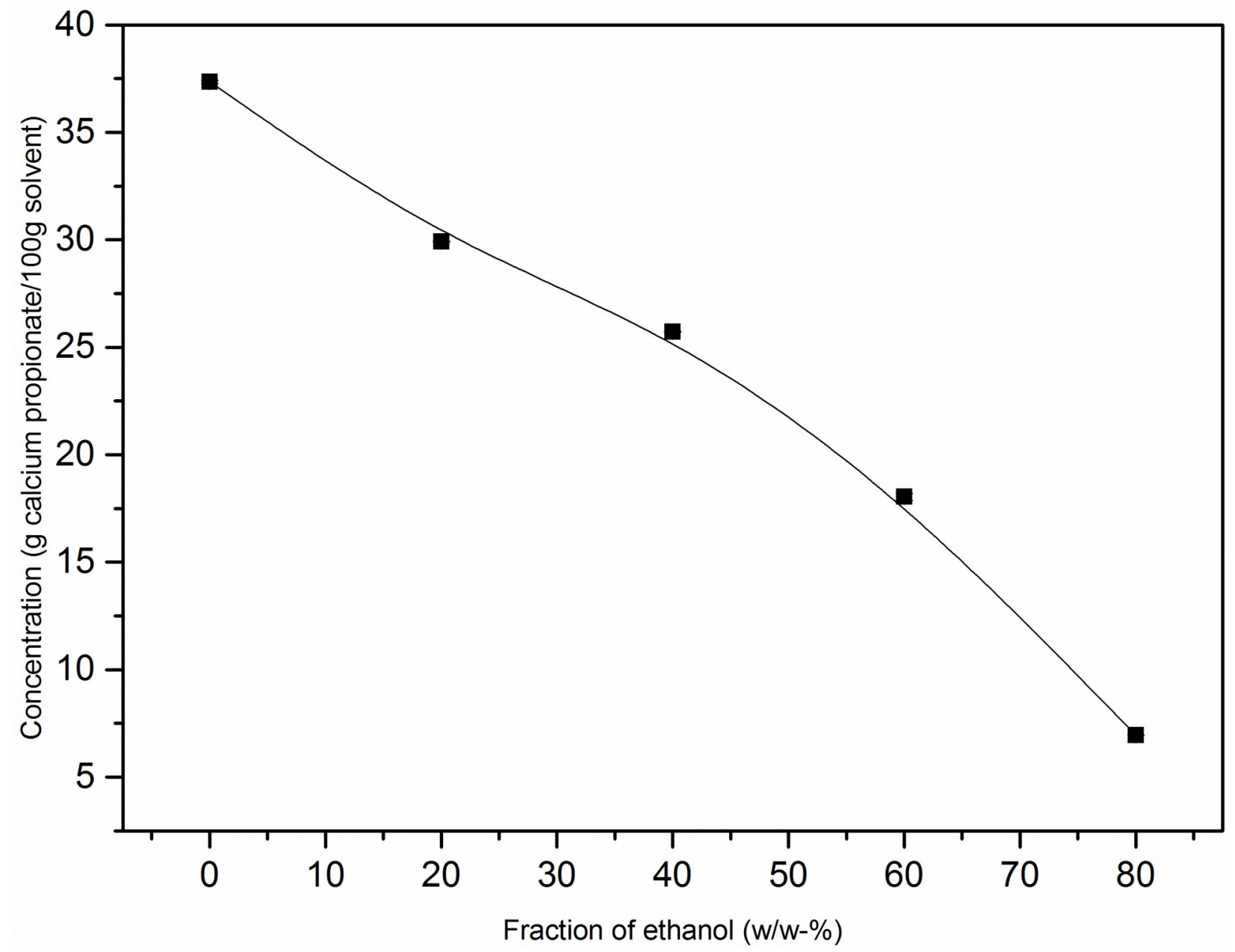


Figure 6. XRPD patterns of calcium propionate (as bought) at different temperatures on heating and cooling (from bottom to top) for studying the solid-state behavior with regard to temperature. " $\mathrm{H}$ " and “A” represent monohydrate and anhydrous calcium propionate phases, respectively.

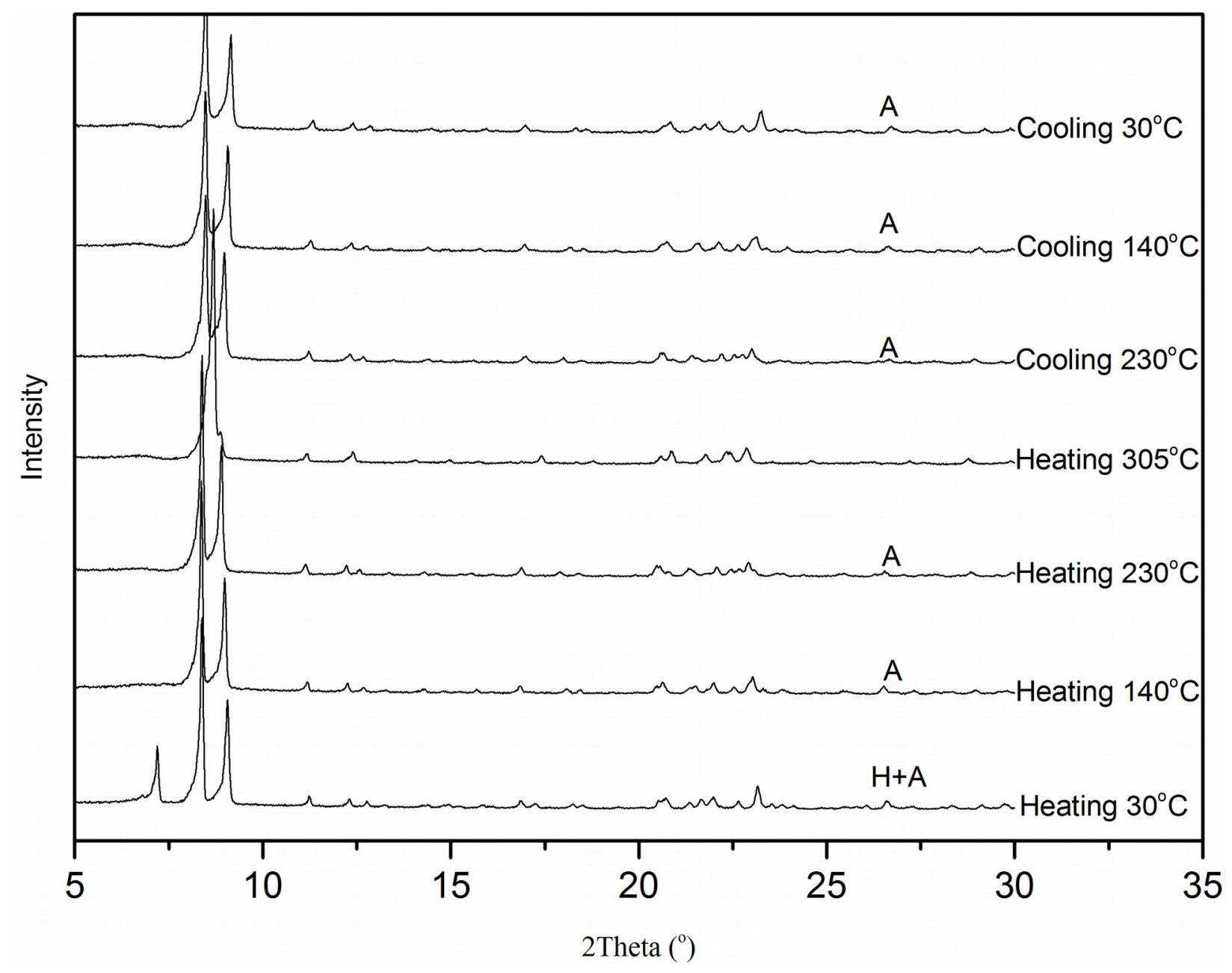


Figure 7. TG-DSC curve of calcium propionate (as bought).

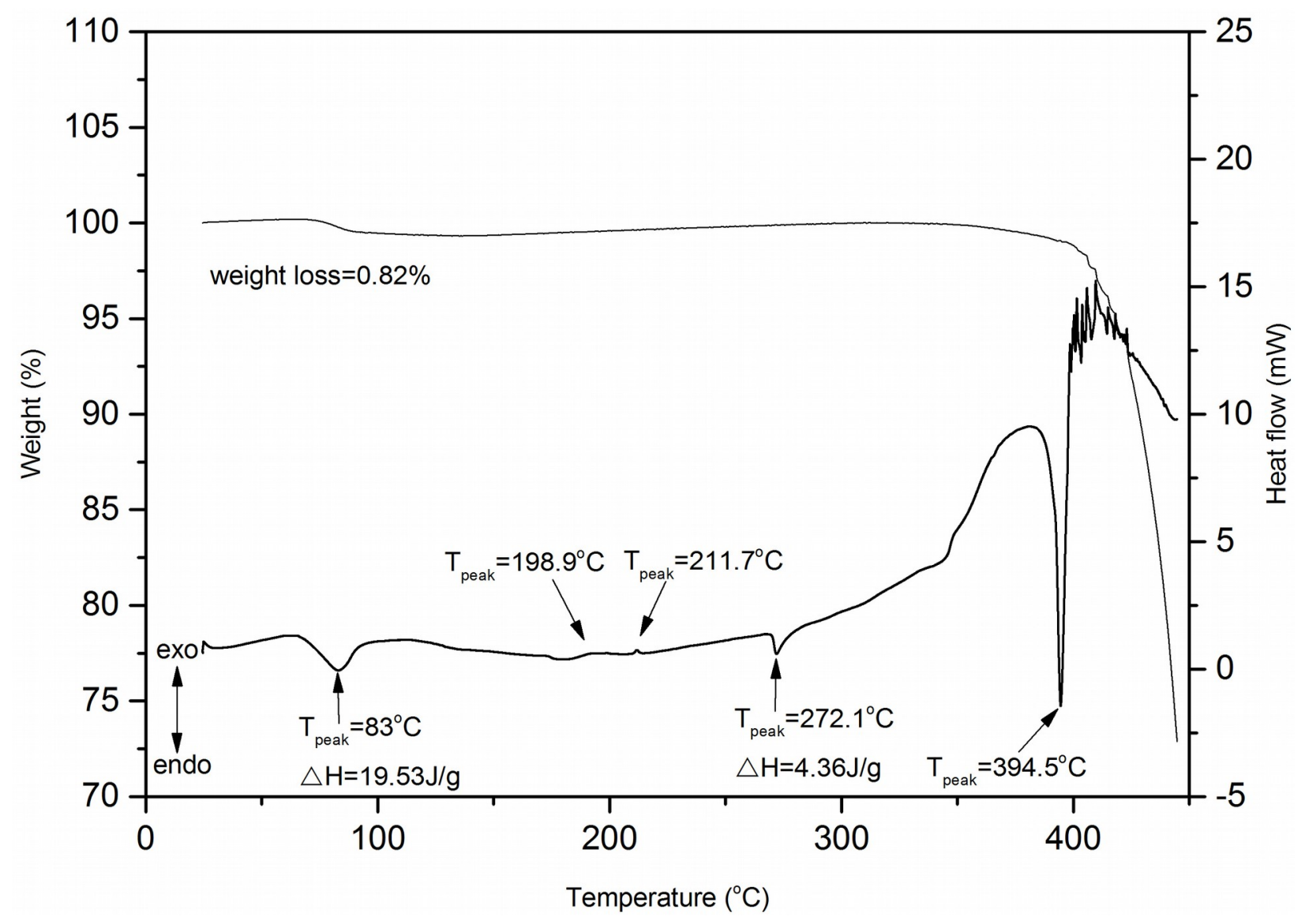


Figure 8. Overlay of DSC curve of calcium propionate (as bought).

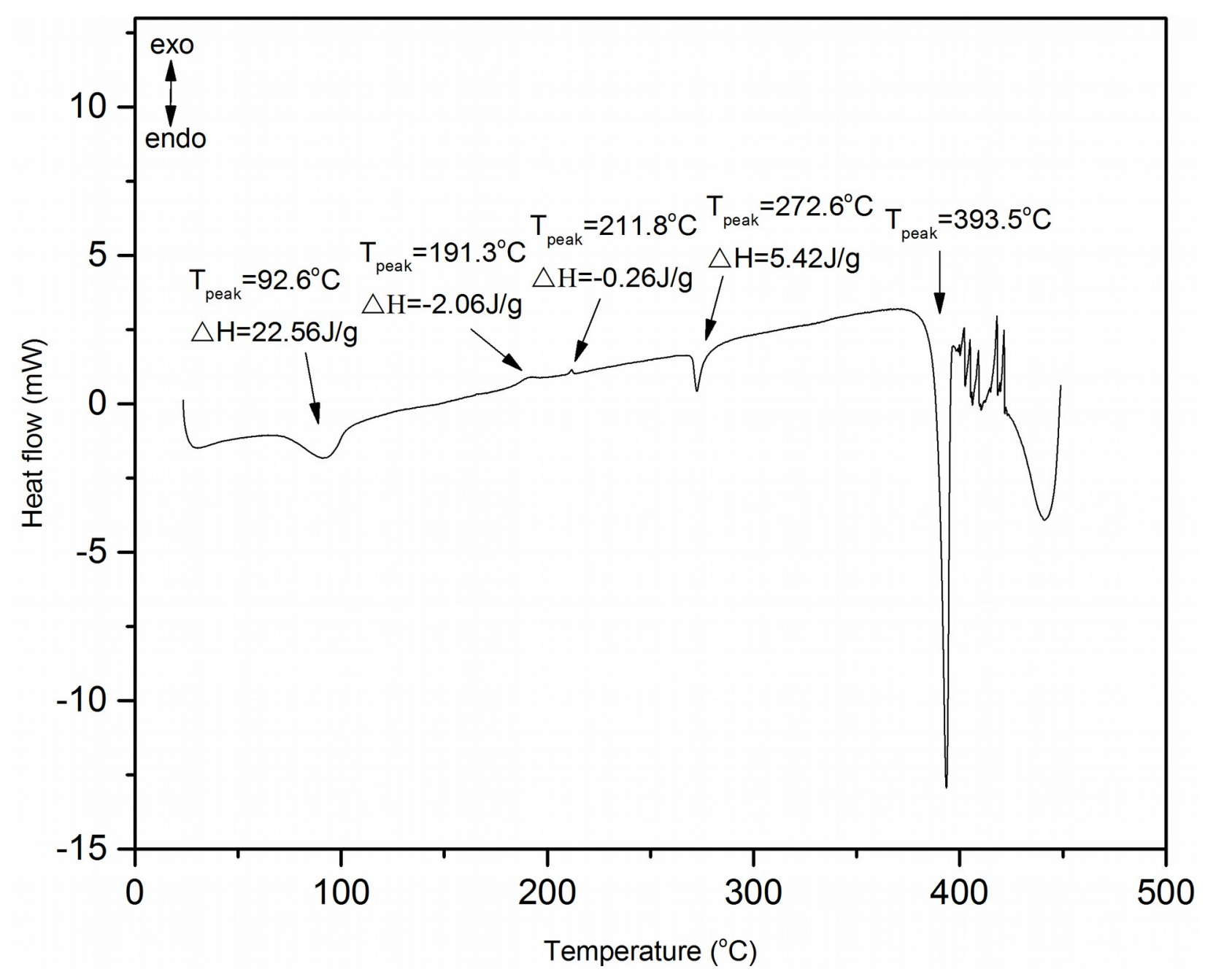


Figure 9. Four different materials investigated in this work: (a) mixture of the anhydrous calcium propionate Form I and the monohydrate as taken from bottle bought from company; (b) monohydrate obtained from solids suspended in aqueous solution at $30^{\circ} \mathrm{C}$; (c) anhydrous calcium propionate Form I prepared by recrystallization and drying of saturated aqueous solution at $30^{\circ} \mathrm{C}$ in oven at $150^{\circ} \mathrm{C}$ and under atmospheric pressure; (d) anhydrous calcium propionate Form II that is formed when calcium propionate is heated up to $305^{\circ} \mathrm{C}$ with a phase transition temperature of around $270^{\circ} \mathrm{C}$ ( $\mathrm{T}_{\text {onset }}$ of TG-DSC/DSC); The mixture of the anhydrous calcium propionate Form I and the monohydrate was used as starting materials in the experiments. " $\mathrm{H}$ " and "A" represent monohydrate and anhydrous calcium propionate phases, respectively.

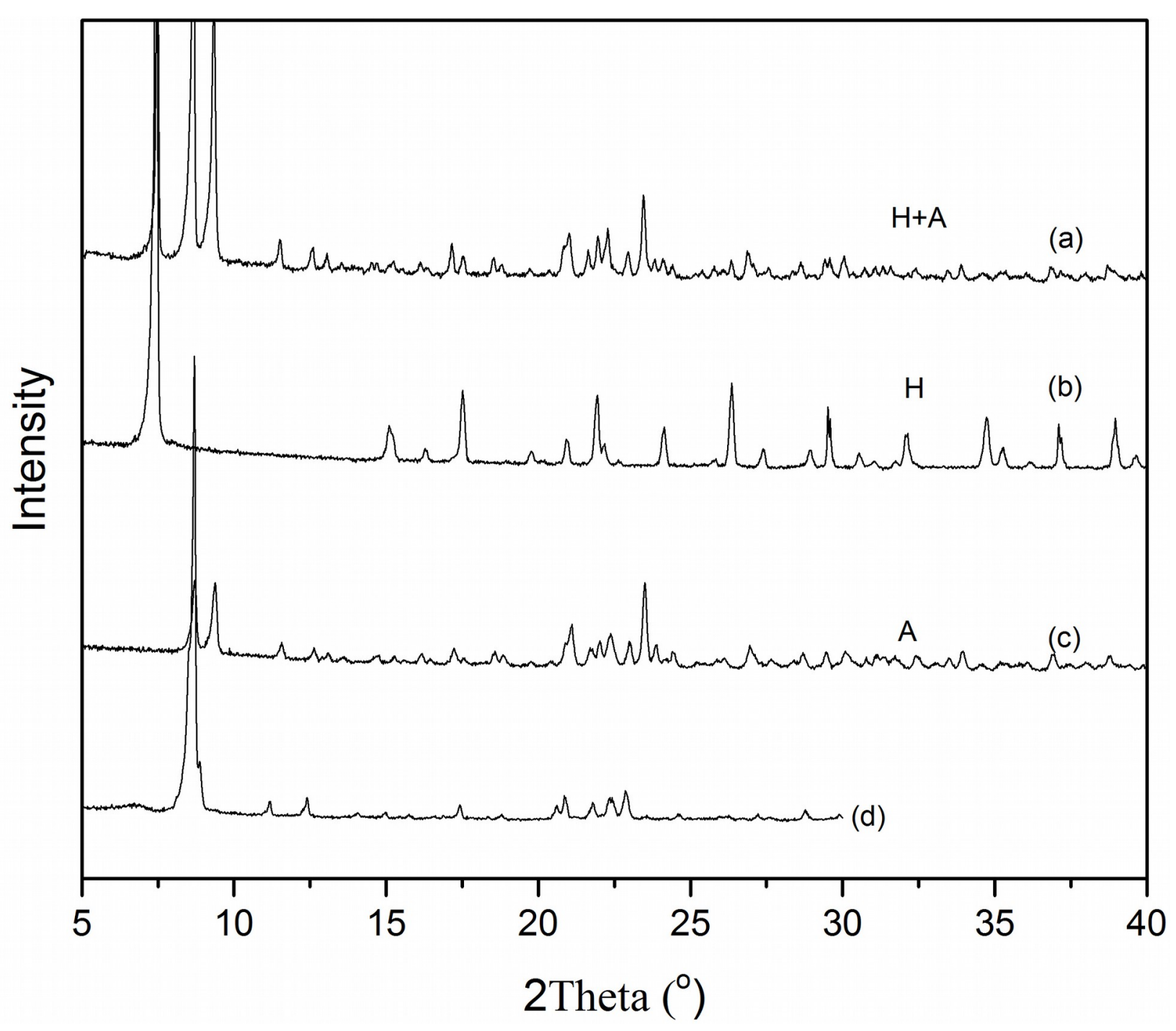




\section{Tables}

Table 1. Solubilities of calcium propionate in water / (g calcium propionate/ $100 \mathrm{~g}$ water)

\begin{tabular}{|c|c|c|c|c|c|}
\hline \multirow[t]{2}{*}{ Temperature /( $\left.{ }^{\circ} \mathrm{C}\right)$} & \multicolumn{2}{|c|}{$\begin{array}{l}\text { Krasnicki } \\
\text { ref. [11] }\end{array}$} & \multirow[t]{2}{*}{$\begin{array}{l}\text { Lumsden } \\
\text { ref. [12] }\end{array}$} & \multicolumn{2}{|c|}{ This work } \\
\hline & $\begin{array}{l}\text { Cooling } \\
\text { method }\end{array}$ & $\begin{array}{l}\text { Heating } \\
\text { method }\end{array}$ & & $\begin{array}{l}\text { Without further } \\
\text { purification }\end{array}$ & $\begin{array}{l}\text { Purification by } \\
\text { recrystallization }\end{array}$ \\
\hline 0 & & & 42.8 & & \\
\hline 0.2 & 41.2986 & 41.3216 & & & \\
\hline 5 & & & 41.7 & & \\
\hline 10 & & & 40.95 & 39.90 & \\
\hline 12 & 40.0212 & & & & \\
\hline 13.5 & & 39.8713 & & & \\
\hline 15 & & & 40.35 & & \\
\hline 20 & & & 39.85 & 38.61 & \\
\hline 25 & & & 39.4 & & \\
\hline 25.4 & 38.7072 & 38.7851 & & & \\
\hline 30 & & & 39.05 & 37.35 & 37.28 \\
\hline 35 & & & 38.75 & & \\
\hline 37.6 & & 37.8760 & & & \\
\hline 38 & 37.8247 & & & & \\
\hline 40 & & & 38.45 & 36.70 & \\
\hline 45 & & & 38.35 & 36.35 & \\
\hline 50 & & & 38.25 & 36.53 & \\
\hline 54 & & 37.3806 & & & \\
\hline 55 & & & 38.2 & 36.36 & \\
\hline 55.2 & 37.3598 & & & & \\
\hline 60 & & & 38.25 & 36.43 & 36.18 \\
\hline 64 & 37.6014 & & & & \\
\hline 65 & & 37.6123 & 38.4 & & \\
\hline 70 & & & 38.75 & 36.93 & \\
\hline 75 & & & 39.2 & & \\
\hline 79 & 38.7736 & & & & \\
\hline 80 & & 38.9132 & 39.85 & 37.77 & \\
\hline 85 & & & 40.8 & & \\
\hline 90 & & & 42.15 & & \\
\hline 95 & & & 44.25 & & \\
\hline 100 & & & 48.44 & & \\
\hline
\end{tabular}

